The plants received by the British Museum constituted the other part of Le Testu's collection, and are important because they include many isotypes, that is duplicates of the type specimens held in Paris. The bequest is very valuable because many of these plants have not been available at the British Museum before. The Le Testu bequest fills a gap that has been a cause of difficulty to botanists working in London on floras of, for example, tropical East Africa-a project which is being carried out jointly at the Museum and at the Royal Botanic Gardens, Kew.

The British Museum's herbarium, consisting of preserved flowering plants, bryophytes, lichens, fungi and algae, is available to anyone engaged in work for which they require to study this plant material. The value of the collection is mostly to those who are preparing floras-identification manuals - of the plants of a particular region, and monographs about particular groups of plants. This sometimes requires considerable rethinking of classification, and it is preferable to have preserved specimens to refer to than to have recourse only to written accounts. The collection at the British Museum is about two-thirds of the size of that at Kew, and one and a half times as large as the third national collection which is in Edinburgh.

\section{Marine Sediment Studies}

THe meeting last Thursday of the Marine Studies Group of the Geological Society of Tondon was devoted entirely to recent work on Holocene marine sediments near the British Isles. Six papers at the meeting, organized by Mr A. H. Stride, dealt with sediment deposition in environments ranging from an estuary to the sea floor of the English Channel. It was made clear how factors such as current strength, exposuro and source of sediment material have affected sediment deposition in the past and still do. Unfortunately, only half an hour was allowed for each paper, which was a pity, particularly for a paper on estuarine sediments read by Dr J. E. Prentice. Dr Prentice is in charge of a research team from King's College and Sir John Cass College which has been working on sediments of the Thames Estuary for the past 6 to 7 years.

Various aspects of the work of the team have been published before, but this meeting was the first time that the work as a whole has been summarized. The importance of the research on the Thames cannot be underestimated, for it is inextricably bound up with long-term economic planning of the future of the Thames. Only last week, a new scheme was proposed for a barrier across the river by Professor Hermann Bondi (see p. 800). A further scheme in a wider context which would involve not only the river and the docks, but roads, motorways and airports as well, was also outlined by Mr John F. F. Clarke in last week's New Scientist (Vol. 37, February 22, page 402 ).

The sediments of the Thames Estuary extend over an area of more than 500 square miles, are up to 100 feet thick and are made up of a variety of materials from finely laminated clays to coarse conglomerates. What the sedimentological team found surprising was that all the sediments are mobile, and they would only stop moving if there were a substantial fall in the sea level. Although there is no evidence of an overall increase in silting up of the estuary during the period of research, there had been many changes in the distribution of sediments in the outer regions. A system of channels, the Edinburgh Channels, for example, which was navigable ten years ago is rapidly silting up-other systcms of deep channels, however, seem to form to take its place.

For the purpose of the research, the Thames was divided into three parts: the inner estuary (as far down as Southend), the middle estuary and the seaward outer estuary. In the inner estuary, mud deposition is dominant. Fine clay in suspension enters from upstream and, on meeting the sca-water, flocculates and begins to fall through the water column. This takes up silt and fine sand, and forms a dense suspension of black "fluid mud" which clings to the bed of the river. It is normally kept in motion by water movement, but the fluid mud layer can also flow by gravity into channels and hollows. Erosion of mud banks is apparently reduced to some extent because the Thames embankment is kept in a reasonable state of repair. Shipping, however, has an effect because the washes help in the erosion of mud flats and in keeping the fluid mud in suspension. In the middle estuary, the characteristic sediment is fine sand, although there are also fine clay and coarse pebbles. 'The possible sources of these sediments were described by Dr Prentice.

Mr N. H. Kenyon spoke on the phenomenon of sand ribbons-long ribbons of sediment, known to be up to 4. miles long and up to 200 yards wide, found on the sea floor around the British Isles in most of the areas where the tidal currents have maximum speeds near the surface of the sea of about two knots or more. They can be used to infer present-day transport paths of the bed load, but, because they are not usually preserved, they are of little use as indicators of palaeocurrents. The ribbon pattern may, however, be preserved in negative as linear shell beds, because living organisms have been seen to prefer the more permanent coarse material between the ribbons. It was suggested that the material of the ribbons is a shelly sand that is in a continuous but restricted supply. It is derived mainly from the reworking of relict sediment and from the shelly material of the local benthos.

\section{Looking Backwards for Resonances from a High Energy Physics Correspondent}

ONE of the most exciting aspects of high energy physics in recent years has been the discovery of very large numbers of largely unsuspected resonances and the determination of their properties. A report of a recent experiment performed at the zero-gradient synchrotron at Argonne National Laboratory (A. D. Krisch el al.. Physical Review, 164, 1661 ; 1967) demonstrates clearly for the first time the value of a powerful yet simple new technique for studying such resonances in the pion-nucleon system.

Because these resonances have such short lifetimes that they cannot be "seen" in any direct sense, the traditional methods of determining their masses, widths (lifetimes) and internal quantum numbers have been to look for anomalous variations of total crosssections for scattering processes, and the enhancerl groupings of two (or more) particles in inelastic experi- 